\title{
Emergence of Extended Spectrum Beta-Lactamase-Producing Gram Negative Bacilli among patients with community acquired- Urinary Tract Infection (CA-UTI) in a Community in South West Nigeria.
}

\author{
Adeyeye J.Oke ${ }^{1}$ and Olawale O. Adelowo ${ }^{2}$ \\ ${ }^{I}$ Department of Medical Microbiology, Faculty of Basic Clinical Sciences, Bowen University Teaching Hospital, \\ Ogbomoso, Nigeria. \\ ${ }^{2}$ Environmental Microbiology and Biotechnology Laboratories Department of Microbiology, University of \\ Ibadan, Nigeria.
}

\begin{abstract}
This study investigated the antimicrobial susceptibility pattern of Gram negative bacilli causing UTI in two Hospitals in a cosmopolitan community in South West, Nigeria. BU is a Tertiary-Care Hospital, and SH is a Private General Practitioner Hospital. One hundred (100) urine samples were collected at each station during the six-month study period and analyzed using standard bacteriology procedures. Bacteria were isolated from the urine samples on MacConkey agar, Blood agar and chocolate agar and isolates tested for susceptibility to 28 different antibiotics using the disc diffusion method. Further, isolates showing resistance to ceftazidime were screened for ESBL production by double disc synergy test (DDST). 20 urine samples (16 from $S H$ and 4 from $B U$ ) yielded growth of bacteria which all showed resistance to more than one of the tested antibiotics. The urine samples from a patient yielded growth of two different bacteria species. All isolates showing resistance to ceflazidime $(n=15)$ tested positive for ESBL. Blochemical characterization tests confirmed the ESBL producers as Klebsiella. pneumonia $(n=14)$ and Enterobacter cloacae $(n=1)$. There was an incidence of multiple drug-resistant ESBL producing Gram negative bacilli in this community.
\end{abstract}

Keywords: UTI Klebsiella pneumonia, Enterobacter cloacae, multiple drug-resistance, ESBL Gram negative bacteria

\section{Introduction}

Over the years, and continuing into the present, almost every known bacterial pathogen has developed resistance to one or more antibiotic in clinical use. Some of the bacterial agents of infection presently commanding worldwide attention include Methcilin-resistant, Staphylococcus aureus (MRSA), Vancomycinresistant Enterococcus (VRE), Penicillin-resistant Streptococcus pneumonia (PRSP) (1) and Extended Spectrum beta-lactamase (ESBL)-producing Gram negative bacilli such as E.coli, Pseudomonas aeruginosa. Enterobacter spp and Klebsiella pneumonia (2). Resistance to antimicrobial drugs among bacterial agents of infection is currently a global health problem (Davies and Davies 2010, (3), Marshall and Levy, 2011 (4), resulting in increase illness, death, and health-care cost.

Several factors are known to be responsible for the current widespread occurrence of resistance among bacterial agent of infection in developing countries. These include, uncontrolled availability of antimicrobial drugs outside of recognized treatment Centers and their use without medical authorization; poor laboratory facilities and trained staff for proper diagnosis of infections, inadequate infection control procedures in hospitals which often result in the spread of infectious disease and resistant strain within and outside the hospital environment (5). Extended-spectrum beta-lactamase (ESBL) - type bacteria have joined the growing number of antibiotic resistant pathogens that cause nosocomial infections (6). The first report of ESBLs appeared in 1983 (7). The widespread use of third generation cephalosporins, and aztreonam is believed to be the major cause of the mutations of ESBL enzymes that are plasmid-mediated capable of hydrolyzing and inactivating a wide range of beta-lactams (8). While ESBL-producing organisms were previously associated with hospitals and institutional care, these organisms are now increasingly found in the community (9-10).

Urinary tract infections are common in clinical practice in Nigeria, however the lack of proper documentation of antimicrobial susceptibility pattern of bacterial agent of UTI is a serious treatment to empirical therapy. Very little information is available about the prevalence of ESBL production among causative agents of UTI in the community where this study was carried out. The aim of this study was to examine prevalence of ESBL production among bacterial agents of UTI from two hospitals in Ogbomoso, a community in South Western Nigeria. 


\section{Materials and Methods}

\subsection{Materials}

MacConkey (Mcc) agar

Blood Agar (BA)

Chocolate agar $(\mathrm{CHO})$

Mueller Hinton (MH) agar (Biotec Medical market Ltd UK)

Petri dish (Sterilin, UK)

Sterile Universal tube (Sterilin, UK)

Antibiotic discs (Oxoid Ltd, UK)

\section{2 Methods}

Midstream urine (MSU) was collected in sterile universal bottles from 100 out-patients each reporting in the two study centers with symptoms of urinary tract infections (UTI) within a six months period. Short histories including age, sex, race, use of antibiotics and international travels in the previous six months were taken from each patient. Macroscopic and Microscopic examinations were done on each sample before culturing on McConkey agar, blood agar and chocolate agar, and incubated (chocolate agar plates in $\mathrm{CO}_{2}$ environment) for 24 hours at $37^{\circ} \mathrm{C}$. Pure isolates were identified as described by Monica ( (5). Antibiotic susceptibility testing was carried out on $\mathrm{MH}$ agar by disc diffusion as recommended by Clinical and Laboratory Standards Institute (CLSI 2011)(11) using discs (OXOID) containing the following antibiotics nitrofurantoin (300 $\mu \mathrm{g})$, streptomycin $(10 \mu \mathrm{g})$, sulphamethoxazole/trimethoprim $(25 \mu \mathrm{g})$, ofloxacin $(5 \mu \mathrm{g})$ perfloxacin $(5 \mu \mathrm{g})$, ciprofloxacin $(5 \mu \mathrm{g})$ tiniflox (norfloxacin + tinidazole), nalidxic acid $(30 \mu \mathrm{g})$, gentamicin $(10 \mu \mathrm{g})$, ceftazidime $(30 \mu \mathrm{g})$, cefixime $(5$ $\mu \mathrm{g})$, cefuroxime $(30 \mu \mathrm{g})$, ceftriazone $(30 \mu \mathrm{g})$, cefotaxime (30ug), cefoxitin(30ug), cefepime $(30 \mu \mathrm{g})$, aztreonam $(30 \mu \mathrm{g})$, amoxicillin-clavulanic acid $(30 \mu \mathrm{g})$, piperacillin-tazobactam $(100 / 10 \mu \mathrm{g})$, ertapenem $(10 \mu \mathrm{g})$, imipenem $(10 \mu \mathrm{g})$, fosfomycin $(10 \mu \mathrm{g})$, Kanamycin $(30 \mu \mathrm{g})$, tobramycin $(10 \mu \mathrm{g})$, amikacin $(30 \mu \mathrm{g})$, colistin $(10$ $\mu \mathrm{g})$ and tigcycline $(15 \mu \mathrm{g})$. Isolates showing complete or intermediate resistance to ceftazidime were screened for ESBL production by double disc synergy test (DDST) on Mueller Hinton agar plates by placing cefotaxime $(30 \mu \mathrm{g})$, ceftazidime $(30 \mu \mathrm{g})$,ceftriaxone $(30 \mu \mathrm{g})$, Aztreonam $(30 \mu \mathrm{g})$ and Cefepime $(30 \mu \mathrm{g})$ at a distance of $30 \mathrm{~mm}$ respectively from an amoxicillin $20 \mu \mathrm{g}$-clavulanate $10 \mu \mathrm{g}$ disc. The plates were incubated overnight at $370 \mathrm{C}$ and plates observed for enhancement of zone of inhibition towards the amoxicillin 20ug-clavulanate $10 \mu \mathrm{g}$ $\operatorname{disc}(11)$

\section{Results.}

Urine samples collected from 100 patients attending the out-patient clinics of the two medical facilities in Ogbomoso, South Western Nigeria within the six months period of this study were subjected to analysis for the isolation of bacteria agents of UTI. All the patients aged between 45-60 years reported in the two hospitals with dysuria and lower abdominal pain. All the patients reporting at hospital SH except the female patient with polymicrobial UTI are diabetic and have been on treatment for more than 6 months. Conversely, none of the patients from Hospital BU is diabetic. All patients from the two hospitals have no previous history of UTI and all claimed not to have used any antibiotic prior to reporting in the Hospital. It is difficult to verify this claim, but we do however know that self medication is widespread in the area where this study was carried out as a result of easy access to antimicrobials and other pharmaceutical substances. None of the patient have travelled out of Nigeria in the last six months before hospital appearance, thus there is a high possibility that the infections in the patients are acquired within the community.

Twenty bacteria $(\mathrm{SH}=12, \mathrm{BU}=8)$ were isolated from $19 \%$ of the samples including two from a female patient with polymicrobial UTI from the private hospital. These were identified as species of K. pneumonia ( $\mathrm{SH}=9, \mathrm{BU}=7)$, E. coli $(\mathrm{SH}=2, \mathrm{BU}=1)$ and Enterobacter cloacae $(\mathrm{SH}=1)$. The female patient with polymicrobial UTI was co-infected by $K$. pneumonia and E. cloacae. All of the isolates showed resistance to at least seven of the tested antibiotics. There was universal resistance to nitrofurantoin, tetracycline, nalidixic acid and streptomycin while only one isolate (SH9) was sensitive to gentamicin, ciprofloxacin and ofloxacin. Conversely, all the isolates are susceptible to piperacillin-tazobactam, ertapenem, imipenem, kanamycin amikacin, colistin and tigcycline (Table I). Fifteen isolates made up to $K$. pneumonia $(\mathrm{SH}=9, \mathrm{BU}=5)$ and E. cloacae $(\mathrm{SH}=1)$ showed resistance to ceflazidime. Test for ESBL production by DDST confirmed all the ceftaxidime resistant isolates as ESBL producers. Interestingly, the K. pneumonia SH10 and E. cloacae SH9 isolated from the female patient with plymicrobial UTI both tested positive for ESBL production. In addition, SH9 was the only isolated to show resistance to cefoxitin, an indication that it may be producing an AmpC enzyme in addition to the ESBL. 
Table 1. Drug susceptibility pattern and ESBL production profile of Isolates

\begin{tabular}{|c|c|c|}
\hline ISOLATES & PHENOTYPIC PATTERN OF RESISTANCE & ESBL PRODUCTION \\
\hline$K$ pneumonia BU3 & cot, amc, gen, ofl, nit, tet, nal, str & negative \\
\hline E. coli $\mathrm{BU} 4$ & $\cot$ gms, gen, off, nit, tat, ngl, str. & negative \\
\hline$E$ coil SH14 & $\cot$ and, gen, off, nit, tet, nal, str. & negative \\
\hline E. coli SH15 & cot ams, gen. offlu, nit, tet, nal, str. & negative \\
\hline$K_{\text {pnequmenias } \mathrm{SH} 16}$ & cot, ams, gen, ofl, nit tet, pal stra & negative \\
\hline${ }^{*}$ E. cloacae $\mathrm{SH} 9$ & cot, for, ans, saz, nit, tat, nal, str. & positive \\
\hline K pneumonia SHs & cot, fer, atm, saz, cre, ctx, gen, sip, afl, nit, tat, nal, str & positive \\
\hline$K$ pneumenias SH6 & 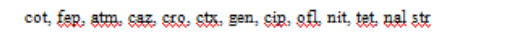 & positive \\
\hline$K_{\text {pnewnonige SHlc }}$ & 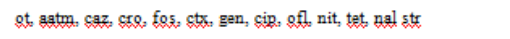 & positive \\
\hline$K_{\text {pneumonias } \mathrm{BU} 1}$ & cot, fer, gtm, saz, cre, cts, gen, cip, off, nit, tat, nal, str & positive \\
\hline$K_{\text {pneumoniag } \mathrm{SH} 2}$ & 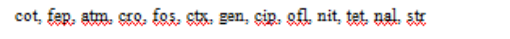 & positive \\
\hline$K_{\text {pneumenias } \mathrm{SH} 3}$ & cot, fer, atm, saz, cre, fos, str, gen, sip, \&t, nit, tat, nal str & positive \\
\hline$K_{\text {pneumeniag } \mathrm{SH} 10}$ & 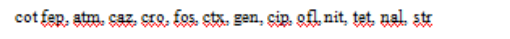 & positive \\
\hline$K_{\text {pneumonias } \mathrm{SH} 11}$ & 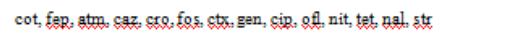 & positive \\
\hline$K$ pneumonia SH12 & 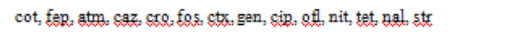 & positive \\
\hline K pneumonia SH13 & 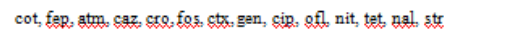 & positive \\
\hline K pneumonia BU2 & cot, fap, atm, caz, sre, fos, cts, gen, sip, afl, nit, tat, nal, str. & positive \\
\hline K pneumonia SH5 & 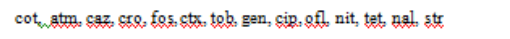 & positive \\
\hline K pneumonia SH7 & 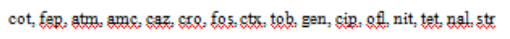 & positive \\
\hline K pneumonia SH4 & 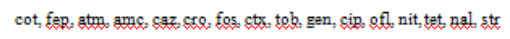 & positive \\
\hline
\end{tabular}

SH: the private hospital; BU: the tertiary care hospital; Cot: Cotrimoxazole; Fox: Cefoxitin; Fep: Cefepine;

Atm: AztreonamAmc: Amoxicillin-clavulanic acid, Caz: Ceftazidime; Cro: Cefiaxone; Fos: Fosfomycin; Ctx: Cefotaxime,

Tob: Tobramycin; Gen: Gentamicin; Cip: Ciprofloxacin; Ofl: Ofloxacin; Nit: Nitrofuratoin; Tet: Tetracycine; Nal: Naldixic

acid; Str: Streptomycin; SH9 and SH10 are from the same patient the only female among the study population to habour as

ESBL producer

\section{Discussion}

Our findings are similar to recent reports of an increasing incidence of ESBL production among causal agents of Community-acquired UTI (CA-UTI). Arne et al reported that CA-UTI is the most common infection caused by ESBL-producing bacteria (10). The emergence of ESBL producing Enterobacteriaceae in this community is worrisome as there is no surveillance programme in place for quick detection and response to such organisms of public health importance. This may facilitate a silent spread of ESBL producing strains with the community and beyond and may create a problem of epidemic proportion. More worrisome is the cooccurrence of two ESBL producing enterobacteria in one patient. A recent study in a UK hospital reported a coincidence of ESBL producing Morganella morganii and Cirobacter freundii in a 67 year old Nigerian who arrived in UK a day before. (12). Although ESBLs have been reported most frequently in E. coli and Klebsiella species, $(13,14)$ none of the three E. coli isolated in the present study tested positive for ESBLs production.

In conclusion, we reemphasize the worrisome emergence of ESBL producing enterobacteriaceae in community acquired infections in Nigeria and the paucity of information on their prevalence as a result of a lack of systematic surveillance programme for pathogens of global public health importance. There is thus an urgent need for a more intensive surveillance and investigation into the prevalence of ESBL- producing Gram negative bacteria in Nigerian healthcare institutions to implement rapid infection control policies.

\section{Acknowledgement}

The authors wish to acknowledge the Medical Director SH for granting the permission in his hospital for this study and the supply of some consumables. 


\section{References}

[1]. Kenneth Todar. Bacterial resistance to antibiotics. Todar' Online Textbook of Bacteriology. Textbook of bacteriology.net/resantimicrobia_2.html

[2]. CDC. Antimicrobial drug resistance in pathogens causing nosocomial infections at a University hospital in Taiwan $1981-1999$. Emerg Inf Dis J 2002; V8, 1

[3]. Davies J. and Davies (2010) Origins and evolution of antibiotic resistance. Microbiol. Mol. Biol Re. 74; 417-435

[4]. Marshall B.M., and Levy, S.B. (2011) Food animals and antimicrobials; impacts on human health. Clin Microbiol Rev: 24:718-733

[5]. Monica C. Medical Laboratory Manual for Tropical Countries (VII) Microbiology. Butterworth Co, $1^{\text {st }}$ ed. 1984

[6]. Christie Bailey. ESBL-type bacteria have joined the growing number of antibiotic pathogens that cause hospital-acquired infections. Suite 101, Mar 25, 2013.

[7]. Knothe TH, Sug LH, Babini GS, et al. Transferable resistance to cefotaxime, cefoxitin, cefamandole, cefuroxime in clinical isolates of Klebsiella pneumonia and Serratia marcescens. Infection. 1983; 11:315-317.

[8]. Medscape News Today. Epidemiology, Detection, and treatment. Pharmacoth 2001; 21:8.

[9]. Wikipedia. ESBL-wikipedia en.wikipedia.org/wiki/Beta-lactamse, Mar 20, 2013

[10]. Arne S, Arrnfinn S, Irene S, et al. Risk factors for CA-UTI caused by ESBL-producing Enterobacteriaceae-a case study in a low prevalence country. PLOSE ONE, 2013, V8 (7) e69581.

[11]. CLSI: Performance standards for antimicrobial susceptibility testing. Twenty first Informational supplements. 2011 ; M100-S21. CLSI, Wayne P.A.

[12]. Soleimanian S, Gordon, N.C., Wareham, D.W. (2011). Polymicrobial necrotizing fasciitis involving Enterobacteria producing CTXM-15 extended-spectrum $\beta$-lactamases. J Med Micro60:135-137

[13]. Pitout JD, Laupland KB. Extended-spectrum beta-lactamase-producing Enterobacteriacease: an emerging public-health concern. Lancet infect dis. 2008; 8: 159-166.

[14]. Palucha A, Mikiewicz B, Hryniewicz W, Gniadkowski M. Concurrent outbreaks of ESBL-producing organisms of the family enterobacteriacease in a Warsaw hospital. J. Antimicrob chemother. 1999; 44:489-99 